\title{
Failure model of soil around enlarged base of deep uplift piles
}

\section{Hong-Fa Xu PhD}

Professor, Department of Civil Air Defense, Engineering Institute of Engineering Corps, PLA University of Science and Technology, Nanjing, China.

2. Quentin Z. Q. Yue PhD, MHKIE, RPE (Geotechnical), PEng Associate Professor, Department of Civil Engineering, The University of Hong Kong, Hong Kong, China
3 Qi-Hu Qian Kandidat Nauk

Academician, Chinese Academy of Engineering, and Professor, Department of Civil Air Defense Engineering, Engineering Institute of Engineering Corps, PLA University of Science and Technology, Nanjing, China
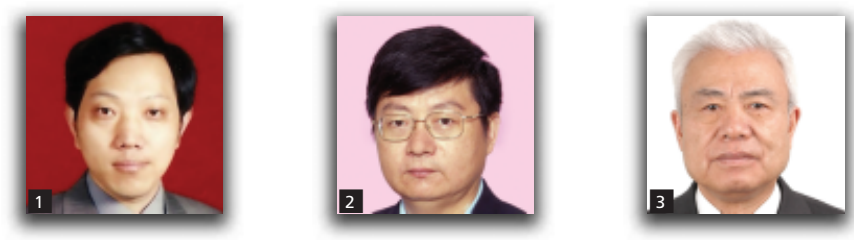

This paper presents an investigation into the failure behaviours of low-cohesive $(c \leqslant 10 \mathrm{kPa})$ or non-cohesive $(c=0)$ soils around the enlarged bases of deep uplift piles. An axisymmetric elasto-plastic finite-element method is used for analysing displacements and plastic strains in the soil-pile system induced by uplifting. Numerical results are examined in detail to reveal the relationships of the accumulated equivalent plastic strain contours in soils and the uplift displacements of piles with the diameters of enlarged bases. The investigation finds that for the pile to reach ultimate uplift failure, the pile has to experience a large upward displacement. A serviceability failure limit of pile upward displacement equal to $10 \%$ of pile shaft diameter is adopted for determining pile uplift resistance capacity. At serviceability failure limit, examination of the accumulated equivalent plastic strain contours in the soils leads to the establishment of two logarithmic spiral functions for the estimation of the plastic zone envelope and the slip surface around the enlarged base. The plastic zone envelopes and slip surfaces are axisymmetrical, peach-shaped, closed and curved surfaces, completely beneath the ground surface. The models and functions have been used to formulate analytical solutions for estimating uplift resistance capacity for deep piles with enlarged bases.

\section{Notation}

$a$ and $b$

the constant parameters

soil cohesion

diameter of the pile shaft

diameter of the spherical base

the coefficient of earth pressure at rest

the buried pile length between the ground

surface and the centre of the spherical base

$D / d$

$N \quad$ the total computational incremental step for

equivalent plastic strain

$N_{\mathrm{c}} \quad$ dimensionless factor of uplift resistance capacity with respect to cohesion

$N_{\mathrm{q}} \quad$ dimensionless factor of uplift resistance capacity with respect to surcharge

$N_{\gamma} \quad$ dimensionless factor of uplift resistance capacity with respect to self-weight

\section{$Q_{\text {bu }}$}

$\bar{r}_{0}$

$r_{0}$

$r_{\mathrm{p} 0}$

$r_{\mathrm{pi}}$

$r_{\mathrm{pr}}$

$z_{p}$

envelope

$\beta_{1}, \beta_{2}$ and $\beta_{3}$ the fitting parameters $\delta$ the frictional angle between pile and soil $\hat{\varepsilon}^{p l}$ base uplift resistance capacity at the serviceability failure limit the polar coordinate variable in the radius a dimensionless original radius the initial radius of logarithmic spiral slip surface initial radius of the plastic zone envelope the distance from the top of the plastic zone (at $\theta=\pi$ ) to the spiral centre $O$

the distance from on the rightmost point of the plastic zone (at $\theta=90^{\circ}+\varphi$ ) to the spiral centre the depth to the vertex of the plastic zone the accumulated equivalent plastic strain over the total computational incremental step $N, \Delta \hat{\varepsilon}_{j}^{p l}$ the $j$ th equivalent plastic strain increment 
the internal frictional angle of soil

$\gamma_{s}^{\prime}$ the soil effective unit weight above the plastic zone the soil unit weight within the plastic zone

$\theta$ the polar coordinate variable in the hoop angle $\xi_{D} \quad$ reduction factor to the coefficient of lateral pressure acting on pile shaft

\section{Introduction}

Piles have been widely used to support uplift loads for many structures, which can be classified as

(a) tension cables such as guyed mast and suspension bridges

(b) high towers for transmission lines and tall chimneys

(c) marine floating platforms for oil drill platforms and offshore airports

(d) mooring systems for ocean surface

(e) shallowly embedded structures in high groundwater table regions for underground railway and civil defence structures.

The structures are commonly subjected to wind forces, floating forces, wave forces, suspension forces, or combinations of these, that can generate considerable uplift loads to the structure foundations.

Piles with enlarged bases can resist high uplift loads and are costeffective in soils. According to the ratio of the pile embedment depth $L$ to the enlarged base diameter $D$, piles with enlarged bases can be further divided into shallowly and deeply embedded piles. It is generally accepted that a critical value of $L / D$ is around 6, based on the results of numerical modelling of circular plate uplift anchors (Ilamparuthi and Dickin, 2000) and those of centrifugal tests on uplift piles with enlarged bases (Dickin and Leung, 1990). For the present paper, piles are defined as shallowly embedded when $L / D<6$, and deeply embedded when $L / D \geqslant 6$. In cases of deeply embedded piles, the soil failure zone around the pile is unable to reach the ground at the serviceability failure limit.

In the past 50 years, a number of researchers and engineers have investigated the behaviour of uniform cross-section piles subject to uplift loads. For example, theoretical investigations have been reported by Ireland (1957), Chattopadhyay and Pise (1986) and Ronold (1990, 1998). Some scaled model tests or field experiments were reported by Ireland (1957), Ismael and Al-Sanad (1986), Lutenegger and Miller (1994), Levacher and Sieffert (1984), Al-Mhaidib and Edil (1998), Lutenegger and Adams (1999), Alawneh et al. (1999) and Mathews et al. (2000).

Literature review of the present studies indicates that there are limited investigations into piles with enlarged bases subject to uplift load in the available publications. Several researchers and engineers investigated shallowly embedded piles with enlarged bases. Dickin and Leung $(1990,1992)$ and Guruno et al. (1998) examined the performance of model piles with enlarged bases shallowly embedded in sand to resist pullout forces using centrifuge facility. Ilamparuthi and Dickin (2001a, 2001b) studied the behaviours of model belled piles subject to uplift load in different sands using a static state test. Kulhawy (1985) examined the spread anchors, helical anchors and grouted anchors that are similar to piles with enlarged bases. In particular, Kulhawy (1985) and Dickin and Leung (1990) studied the shear slip failure surfaces and the corresponding design methods and formulations for the spread anchors subject to uplift loads in sand. The failure envelope surfaces include the vertical cylindrical slip surface model, the inverted truncated cone model, and the curved slip surface model.

Although the results for shallow anchors can be used for the design of shallowly embedded piles with enlarged bases, they are not directly applicable to deeply embedded piles with enlarged bases. For deeply embedded piles with enlarged base, investigation results are very limited. Deeply embedded piles with enlarged base such as belled drilled shafts, rammed bulb pile, or explosiveenlarged base pile can gain a large uplift resistance capacity through soil surcharge above the enlarged base. It is not an easy task to quantify accurately and quickly the uplift resistance capacity that a deep pile with an enlarged base may have.

The failure zone model proposed by Meyerhof and Adams (1968) and used by Tomlinson (1981) is presented in Figure 1(a). Figure 1(b) shows a failure zone for a deep spread anchor in weak and compressible soils. This model is proposed by Kulhawy (1985). They assumed that the shear slip failure surface above the anchor was not fully mobilised before the anchor punched through the soil in a bearing capacity type of failure. Figure 1(c) shows another failure zone for an uplift cylindrical anchor deeply embedded in sand. This model was proposed by Hsu and Liao (1998) and Ghaly (1999) based on numerical analyses using a finite-difference method. Uplift resistance can be estimated using three failure models for the anchors.

To predict accurately the uplift resistance of the deep pile with enlarged base, it is necessary to establish a failure model in various soils. The failure model of soil should be related to soil properties (mainly cohesion $c$ and internal friction angle $\varphi$ ), shaft diameter and the diameter of enlarged base, and so on.

The objective of this paper is to establish a more rigorous failure zone model of soil for estimating uplifting resistance of a deep pile with enlarged spherical base. To achieve this objective, the following procedure has been adopted.

(a) The finite-element method is used to compute the stress and displacement distributions for a cylindrical pile with an enlarged spherical base that is deeply embedded in a homogeneous soil layer.

(b) Based on the numerical results, a detailed examination is carried out of the failure zone geometries through the soil adjacent to the enlarged base.

(c) Based on the failure pattern obtained, use is made of the 
Failure model of soil around enlarged base of deep uplift piles

Xu, Yue and Qian
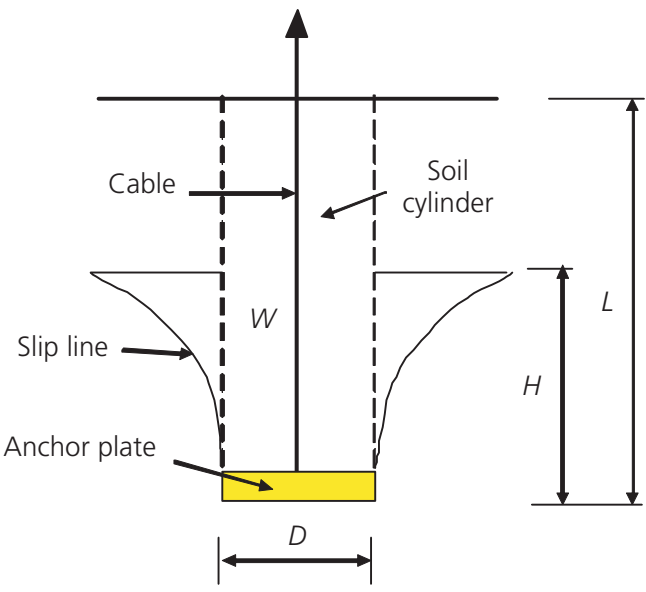

$L$ : depth of anchor plate

$H$ : height of slip-mass

$D$ : diameter of anchor plate

$W$ : weight of soil cylinder above anchor plate

(a)

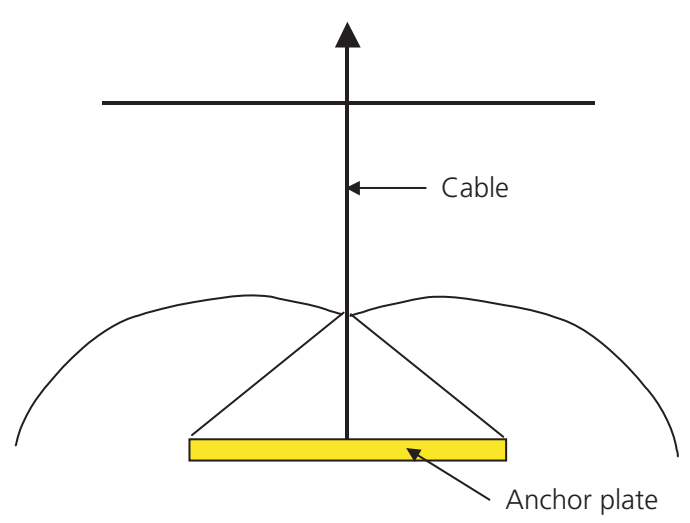

(b)

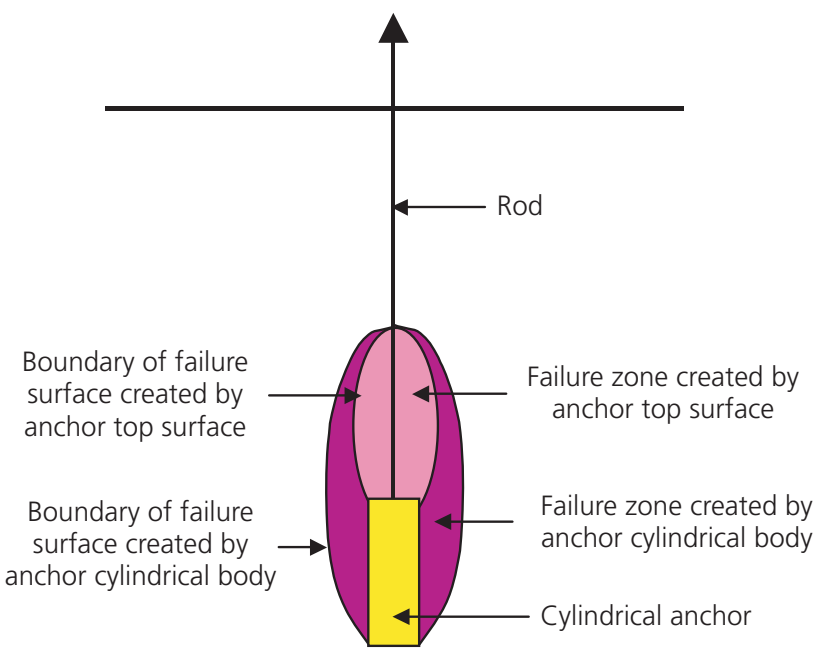

(c)

Figure 1. Slip surface models adopted for estimating uplift resistance ground anchors with enlarged bases: (a) after Tomlinson (1981); (b) after Kulhawy (1985), and ASCE; (c) after Ghaly (1999) logarithmic spiral function to describe the failure zone envelopes.

(d) Analytical functions are further established to estimate the envelope surface of the plastic zones and slip surfaces surrounding the cylindrical piles with enlarged spherical base deeply embedded in soils. These analytical equations of the failure models of soil will be very important for estimating the uplift resistance capacity of a deep pile with enlarged base.

\section{Models for finite-element analysis}

2.1 Boundary value problem and constitutive models for pile uplifting

Figure 2 shows the computation model used in the finite-element analysis. In this model, a cylindrical pile of shaft diameter $d$ is deeply embedded in a homogeneous soil. The pile has an enlarged base of spherical shape with diameter $D$. The pile head is subjected to an uplift load $U_{0}$. The pile length $L$ is assumed to be $10 \mathrm{~m}$ for the series of analyses. The other boundary conditions are also given in Figure 2. All elements are axisymmetric on left vertical boundaries. Various uplift forces apply at the pile top for calculation and various uplift states corresponding with each increment load, until a force arrives at an ultimate state. Displacement restrictions are imposed on the boundary nodes.

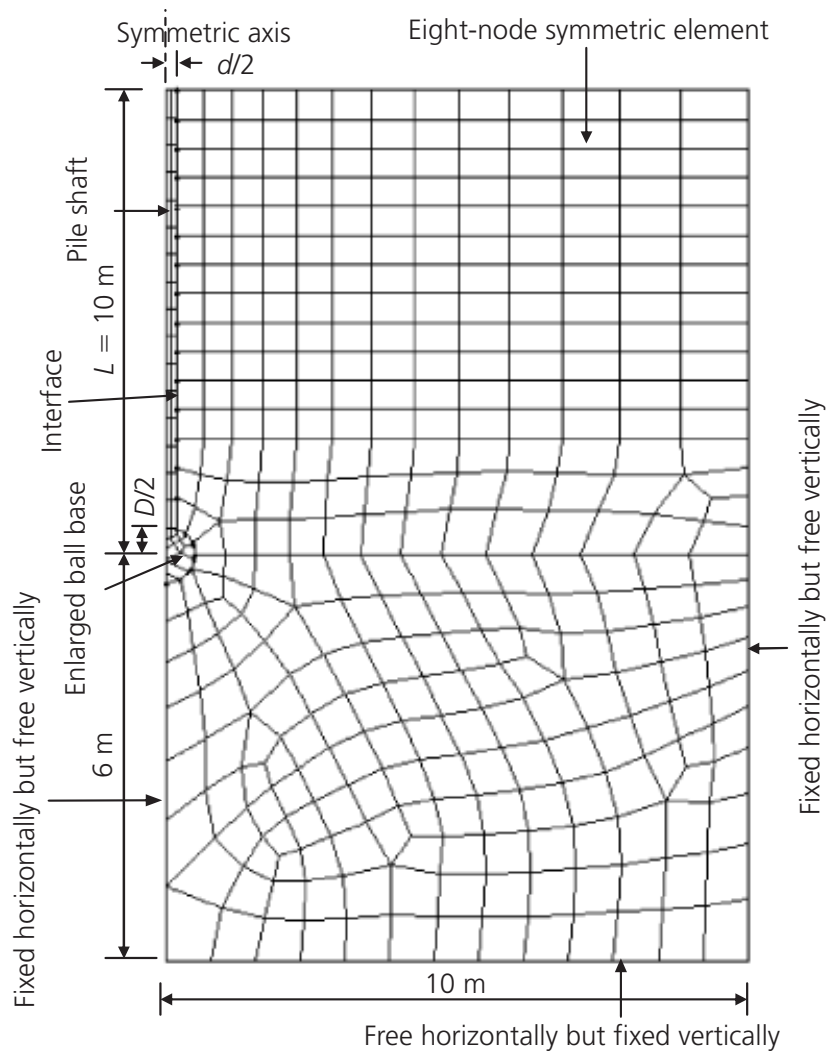

Figure 2. FEM model for an elasto-plastic analysis of a pile with enlarged spherical base and deeply embedded in soils 
All nodes in the vertical boundaries are fixed horizontally but freed vertically. Similarly, all nodes in the bottom boundaries are freed horizontally but fixed vertically.

This model represents an axisymmetric boundary value problem. Such axisymmetric models for examining single piles have been adopted by many researchers, including Ellison et al. (1971), Balaam et al. (1975), Hsu and Liao (1998), Mohamedzein et al. (1999), Liyanapathiranal et al. (2000), Ilamparuthi and Dickin (2000) and Lee et al. (2002).

In the finite-element method (FEM) numerical analysis, the constitutive relationships for the pile, the surrounding soil and the pile-soil interface are assumed as follows.

(a) The pile material is a linear elastic solid when there is not large stress in the pile.

(b) The surrounding soil is an elasto-plastic material satisfying the Drucker-Prager yield criterion.

(c) The pile-soil interface is modelled by point-surface contact elements for possible large slip deformation between pile and soil (such as Peric and Owen, 1992).

This model can accommodate large slippage, gap and close contacts along the soil-pile interface. There are three material parameters in the pile-soil interface model, namely the shear sticking stiffness, the normal contact stiffness and the coefficient of sliding friction; they satisfy the Mohr-Coulomb frictional law. The pile-soil interface model has been explained by Kohnke (1997) and Xu et al. (2002).

\subsection{Calculation schemes}

To examine the failure zone of a pile subject to uplifting, a finiteelement analysis is performed of the pile-soil problem in Figure 2. Five numerical schemes, termed scheme Nos 1-5, are examined. The typical parameters of pile and soils used in the analysis are listed in Table 1. Schemes No. 1 and No. 2 are the basic schemes to study the whole uplift behaviour of the pile in clay and sand, respectively. Scheme Nos 3, 4 and 5 have the same pile and soil parameters as those of scheme No. 1 but the pile base diameters are different. These three schemes are used to examine the effect of different spherical base diameter on uplift bearing capacity.

An axisymmetric finite-element analysis is carried out for the five schemes. The uplift load at the pile head is added incrementally and monotonically until the uplift load reaches an ultimate stage. The finite-element software package Ansys version 5.4 (Kohnke, 1997) was used in the numerical computation. Results of the numerical analysis are presented and discussed in the following section.

\section{Soil failure zones due to pile uplifting}

\subsection{Equivalent plastic strain}

In this section, an analysis is given of the results for scheme Nos $1-5$. Focus is placed on the relationship between the pile upward displacement, diameter of enlarged base and the soil failure behaviour.

For evaluating the plastic zones in the soil, the present authors adopted the concept of accumulated equivalent plastic strain that is defined as follows by Kohnke (1997)

$$
\hat{\varepsilon}^{\mathrm{pl}}=\sum_{1}^{N} \Delta \hat{\varepsilon}_{j}^{\mathrm{pl}}
$$

where $\hat{\varepsilon}^{\mathrm{pl}}$ is the accumulated equivalent plastic strain over the

\begin{tabular}{|c|c|c|c|c|c|c|}
\hline \multicolumn{2}{|l|}{ Scheme No. } & 1 & 2 & 3 & 4 & 5 \\
\hline \multicolumn{2}{|c|}{ Pile diameter, $d: m$} & 0.5 & 0.5 & Same as $t$ & cheme & \\
\hline \multicolumn{2}{|c|}{ Pile length, $L: m$} & 10 & 10 & & & \\
\hline \multicolumn{2}{|c|}{ Enlarged base ball diameter, $D: m$} & 1.0 & 1.0 & 0.7 & 1.4 & 1.8 \\
\hline \multirow[t]{5}{*}{ Soil parameters } & $\mathrm{c}: \mathrm{kPa}$ & 10 & 0 & Same as $t$ & cheme & \\
\hline & $\phi:$ deg & 20 & 35 & & & \\
\hline & Elastic modulus, $E_{s}: \mathrm{kPa}$ & $3 \times 10^{4}$ & $5 \times 10^{4}$ & & & \\
\hline & Poisson ratio, $\mu_{s}$ & $0 \cdot 38$ & $0 \cdot 3$ & & & \\
\hline & Unit weight, $\gamma_{s}: k N / m^{3}$ & 18 & 18 & & & \\
\hline \multirow[t]{3}{*}{ Pile parameters } & Elastic modulus, $E_{\mathrm{p}}: \mathrm{kPa}$ & $2.7 \times 10^{7}$ & $2.7 \times 10^{7}$ & & & \\
\hline & Poisson ratio, $\mu_{\mathrm{p}}$ & 0.18 & 0.18 & & & \\
\hline & Unit weight, $\gamma_{p}: k N / m^{3}$ & 25 & 25 & & & \\
\hline \multicolumn{2}{|l|}{ Load type } & Uplift & Uplift & & & \\
\hline \multicolumn{2}{|l|}{ Aim } & $\begin{array}{l}\text { Behaviour in } \\
\text { cohesive soil }\end{array}$ & $\begin{array}{l}\text { Behaviour in } \\
\text { non-cohesive soil }\end{array}$ & $\begin{array}{l}\text { Influence } \\
\text { behaviour }\end{array}$ & $d$ bas & r on uplift \\
\hline
\end{tabular}

Table 1. Values of the soil and pile parameters used in scheme Nos 1-5 
total computational incremental step $N$, and $\Delta \hat{\varepsilon}_{j}^{\mathrm{pl}}$ is the $j$ th equivalent plastic strain increment defined as follows

$$
\Delta \hat{\varepsilon}_{j}^{\mathrm{pl}}=\left[\frac{2}{3}\left\{\Delta \varepsilon_{j}^{\mathrm{pl}}\right\}^{\mathrm{T}} \mathbf{M}\left\{\Delta \varepsilon_{j}^{\mathrm{pl}}\right\}\right]^{1 / 2}
$$

where the superscript $\mathrm{T}$ stands for the transpose of a matrix and

$$
\mathbf{M}=\left[\begin{array}{llllll}
1 & 0 & 0 & 0 & 0 & 0 \\
0 & 1 & 0 & 0 & 0 & 0 \\
0 & 0 & 1 & 0 & 0 & 0 \\
0 & 0 & 0 & 2 & 0 & 0 \\
0 & 0 & 0 & 0 & 2 & 0 \\
0 & 0 & 0 & 0 & 0 & 2
\end{array}\right]
$$

and

$$
\left\{\Delta \varepsilon_{j}^{\mathrm{pl}}\right\}=\left\{\begin{array}{c}
\Delta \varepsilon_{j 11}^{\mathrm{pl}} \\
\Delta \varepsilon_{j 22}^{\mathrm{pl}} \\
\Delta \varepsilon_{j 33}^{\mathrm{pl}} \\
\Delta \varepsilon_{j 12}^{\mathrm{pl}} \\
\Delta \varepsilon_{j 23}^{\mathrm{pl}} \\
\Delta \varepsilon_{j 31}^{\mathrm{pl}}
\end{array}\right\}
$$

\subsection{The two-limit failure stage}

The numerical results indicate that a large pile upward displacement is required to fully mobilise the ultimate uplift resistance that is, the ultimate uplift capacity stage, see Figure 3. From the pile structural serviceability point of view, a much smaller upward displacement could have caused the pile and superstructure system to fail to function. Unacceptable distortion and cracking in the pile and associated structures could have occurred at a smaller upward displacement. Therefore, the present authors have adopted the concept of serviceability failure limit that corresponds to a limit uplift load and a limit upward displacement at the pile head. For the deep piles with enlarged bases, the limit upward displacement is usually much less than the upward displacement at the ultimate failure stage.

Tomlinson (1981) and GEO (1996) have proposed a criterion for the serviceability failure limit that the limit uplift load is the load causing a limit upward displacement equal to $10 \%$ of the least pile diameter in soil. Using this criterion, the limit upward displacement can be determined equal to $50 \mathrm{~mm}(10 \%$ of pile diameter $d=0.5 \mathrm{~m})$. In the following, this criterion will be adopted in the analysis.

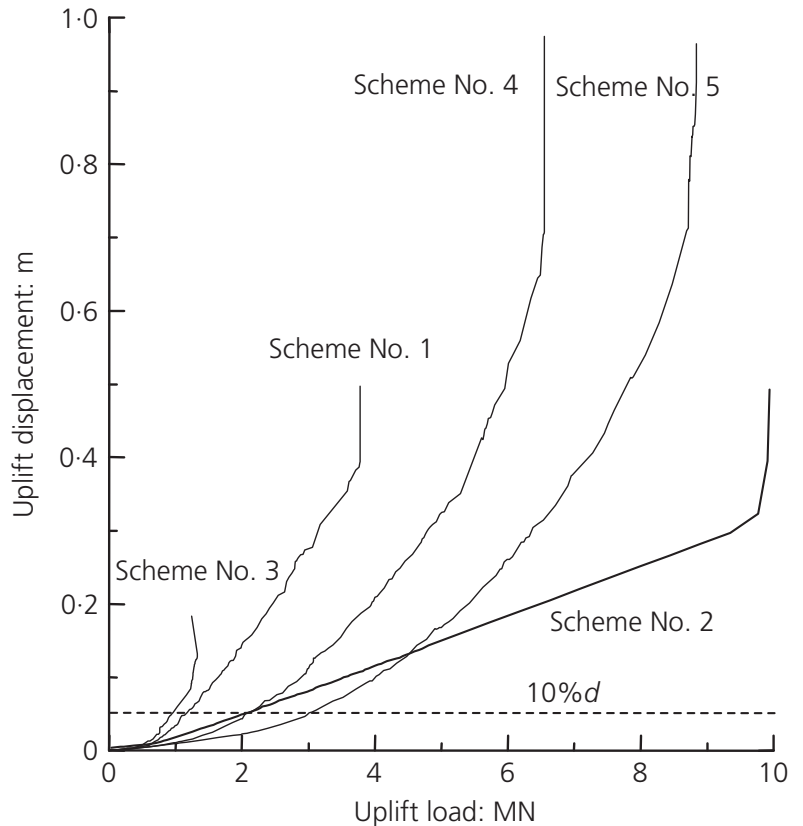

Figure 3. The load-displacement curves for scheme Nos 1-4 at the ultimate uplift capacity stage

\subsection{Plastic zones in low-cohesive soils}

Figure 4 shows the accumulated equivalent plastic strain contours in the low-cohesive soils $(c \leqslant 10 \mathrm{kPa})$ for scheme No. 1 due to the pile uplifting at the serviceability failure limit. Figure 5 shows the accumulated equivalent plastic strain contours at the ultimate failure stage. The soil plastic yielding starts at the region near the enlarged base and propagates gradually upwards with the increase in the pile upward displacement until the ultimate failure stage (ultimate failure displacement is $396.4 \mathrm{~mm}$ ). For the plastic zone envelopes, the major axis is along the vertical direction and the minor axis is along the horizontal radial direction. This result is similar to the failure envelope in Figure 1(c).

In particular, the value of contours $\mathrm{A}$ in Figures 4 and 5 (equal to $10^{-6}$ ), can be used as the plastic zone envelopes for the two limiting stages, respectively. The major and minor axis lengths are approximately equal to 4.4 and $3.9 \mathrm{~m}$ at the serviceability failure limit, and 9.5 and $8.8 \mathrm{~m}$ at the ultimate failure stage, respectively. The plastic zone envelopes can be expressed empirically using the following logarithmic spiral function for best-fit contours A, as shown in Figure 5

1. $r=r_{\mathrm{p} 0} \mathrm{e}^{\theta \tan \phi}$

where $r$ and $\theta$ are the two polar coordinate variables, $r$ is the radius, $\theta$ is the hoop angle, $r_{\mathrm{p} 0}$ is the initial radius $(\theta=0$, direction is vertically downwards), and $\phi$ is the internal frictional angle of the soil. The spiral centre is point $\mathrm{O}$, located at the origin of the polar coordinate system, which is also the centre of 


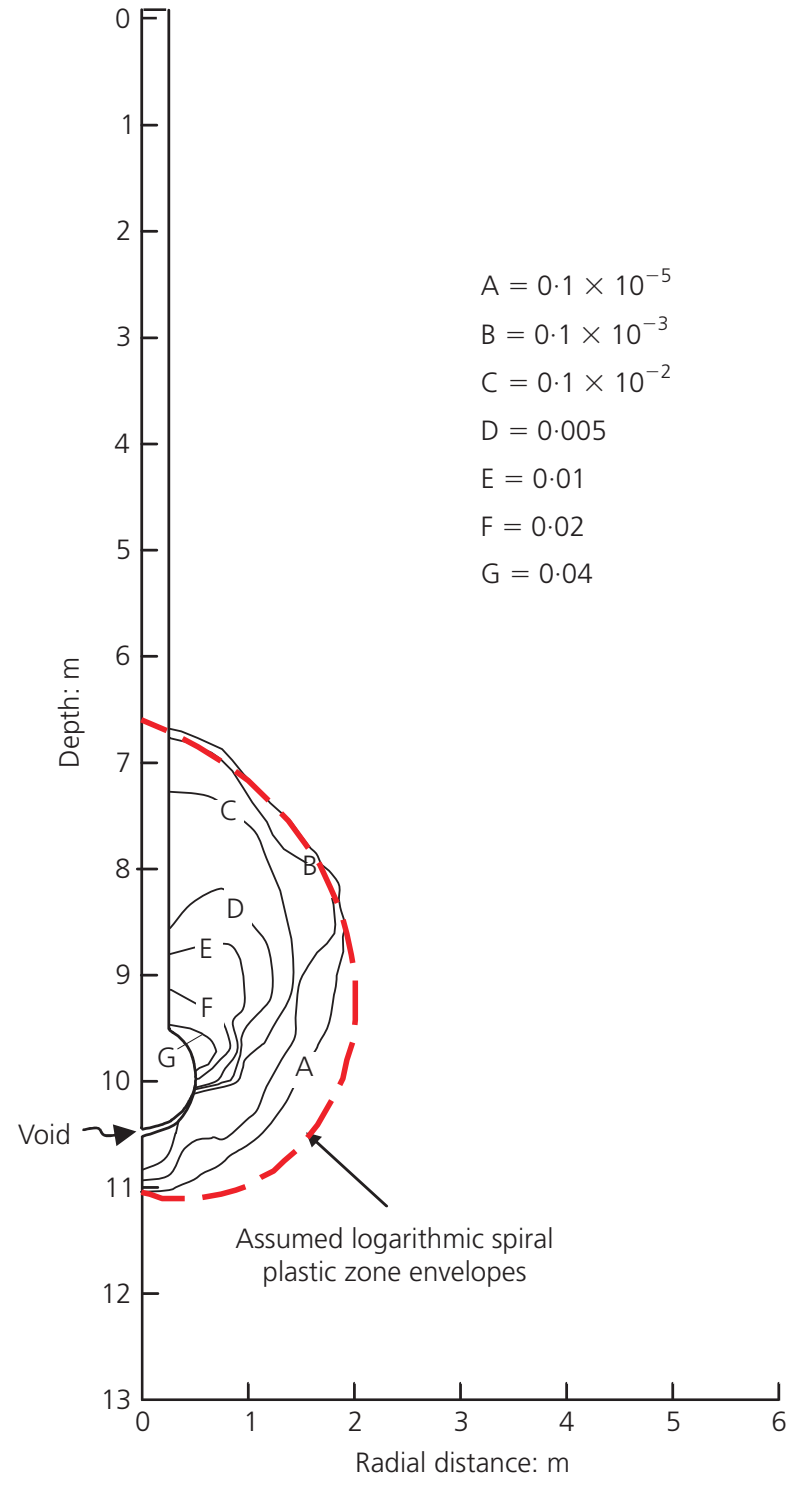

Figure 4. Contours of the accumulated equivalent plastic strains due to the pile uplifting for scheme No. 1 at the serviceability failure limit

the enlarged spherical base at $z=L$. In this paper, the pure cohesive soil (i.e. $\phi=0$ ) is not considered.

Other parameters shown on Figure 6: $r_{\mathrm{pi}}$ is the distance from the top of the plastic zone (at $\theta=\pi$ ) to the spiral centre $\mathrm{O}, r_{\mathrm{pr}}$ is the distance from on the rightmost point (at $\theta=90^{\circ}+\phi$ ) to the spiral centre.

Equation 1 is used to plot the best plastic zone envelopes fitting plastic contours A with a dashed line shown on Figure 4 and Figure 5. On the best plastic zone envelope for scheme No. 1 $\left(c=10 \mathrm{kPa}, \phi=20^{\circ}\right)$ at the serviceability failure limit in Figure 4 , it is found that $r_{\mathrm{p} 0} \approx 1.05 \mathrm{~m}$ (at $\theta=0^{\circ}$ ), $r_{\mathrm{pi}} \approx 3.3 \mathrm{~m}$ (at $\theta=180^{\circ}$ ) and $r_{\mathrm{pr}} \approx 2 \cdot 11 \mathrm{~m}$ (at $\theta=110^{\circ}$ ). On the best plastic

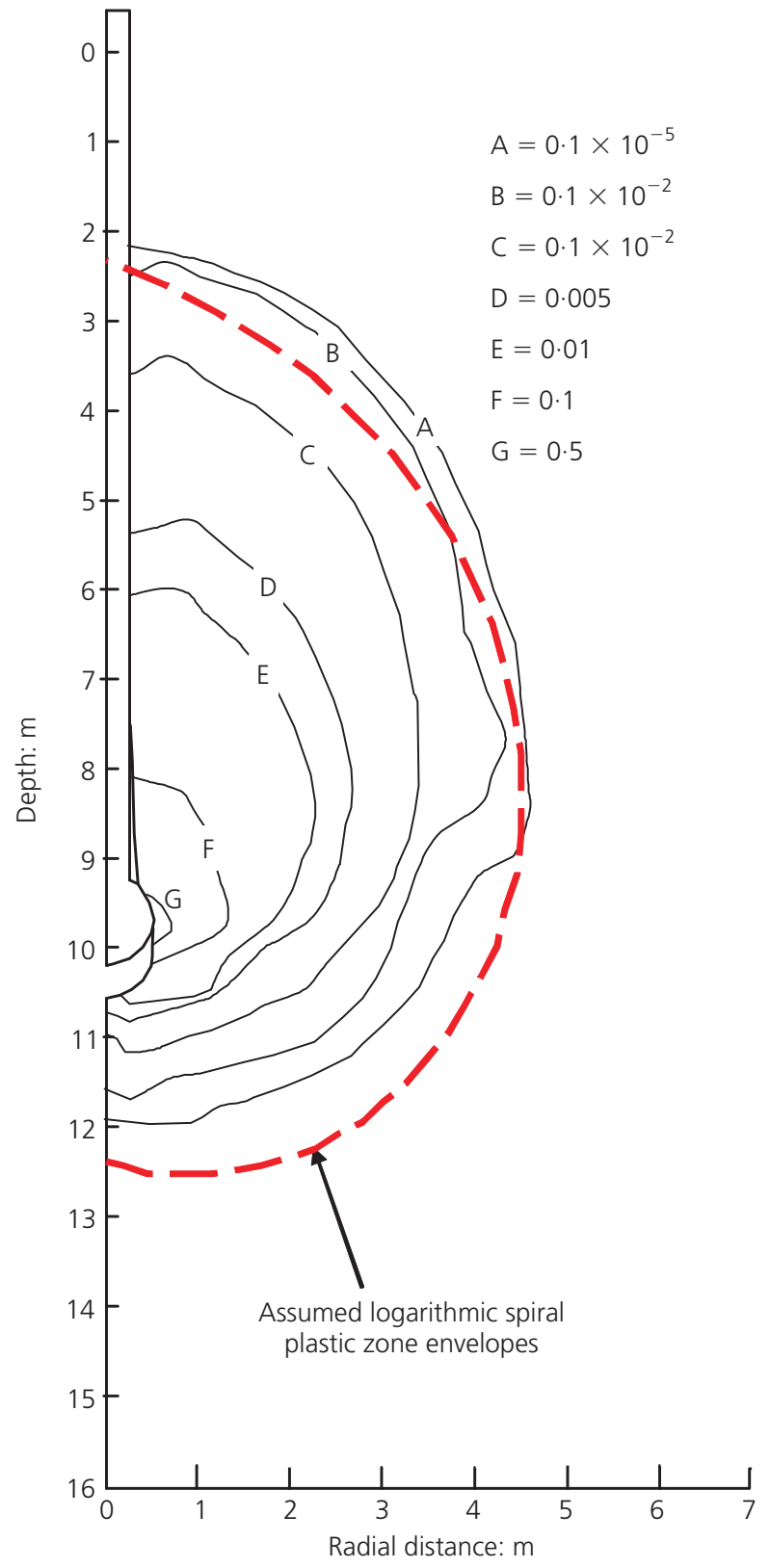

Figure 5. Contours of the accumulated equivalent plastic strains due to the pile uplifting for scheme No. 1 at the ultimate failure stage

zone envelope for scheme No. 1 at the ultimate failure stage in Figure 5, it is found that $r_{\mathrm{p} 0} \approx 2.43 \mathrm{~m}$ (at $\theta=0^{\circ}$ ), $r_{\mathrm{pi}} \approx 7.62 \mathrm{~m}$ (at $\theta=180^{\circ}$ ), $r_{\mathrm{pr}} \approx 4.89 \mathrm{~m}\left(\right.$ at $\theta=110^{\circ}$ ).

\subsection{Plastic zones in non-cohesive soils}

Similarly to the above section, Figures 7 and 8 are used to show the accumulated equivalent plastic strain contours in the noncohesive soils for scheme No. 2 due to the pile uplifting at the serviceability failure limit and at the ultimate failure stage, respectively. 


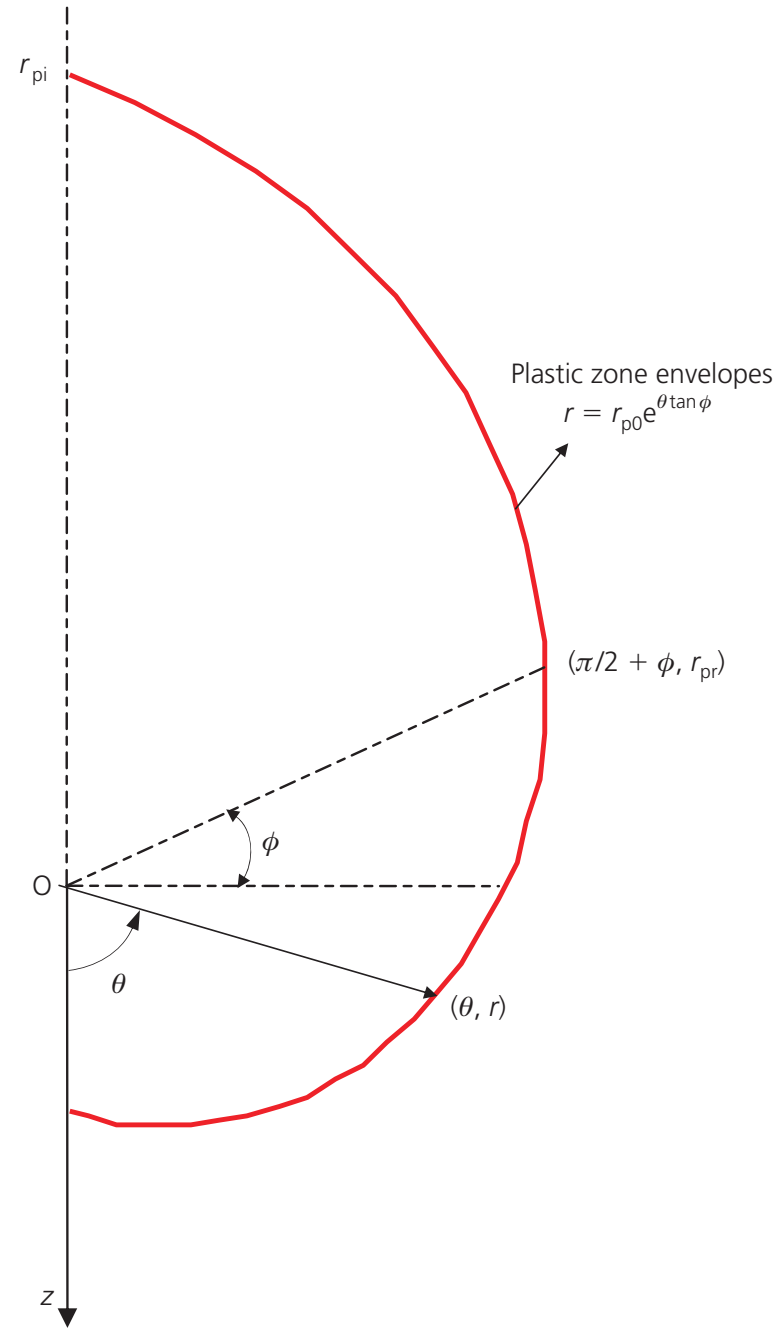

Figure 6. Geometry of the plastic zone envelope

It is evident that the plastic strain contours for scheme No. 2 $\left(c=0, \phi=35^{\circ}\right)$ at the serviceability failure limit in Figure 7 are very similar to those in Figure 4, except that there is a small additional plastic zone in the soil adjacent to the pile head. The plastic zone surrounding the pile base is about $5.6 \mathrm{~m}$ long along the vertical major axis and about $4.2 \mathrm{~m}$ long along the radial minor axis. Using Equation 1, it can be found that the logarithmic spiral has an initial radius $r_{\mathrm{p} 0} \approx 0.54 \mathrm{~m}$ for a best fitting of the plastic strain contour A, $r_{\mathrm{pi}}=4.87 \mathrm{~m}$ (at $\theta=180^{\circ}$ ) and $r_{\mathrm{pr}} \approx 2.49 \mathrm{~m}\left(\right.$ at $\left.\theta=125^{\circ}\right)$ in Figure 7 .

As the pile displacement further increases upwards, the lower plastic zone continues to expand and then becomes connected with the zone at the head, eventually forming a large plastic zone at the ultimate failure stage (ultimate failure displacement is $301.8 \mathrm{~mm}$ ). As shown in Figure 8, the plastic strain contour A has a deep bowl shape, with depth of $12.4 \mathrm{~m}$ and a maximum radius of more than $10 \mathrm{~m}$ on the ground. Considering the limit of right boundary of the finite-element model, the actual radius of

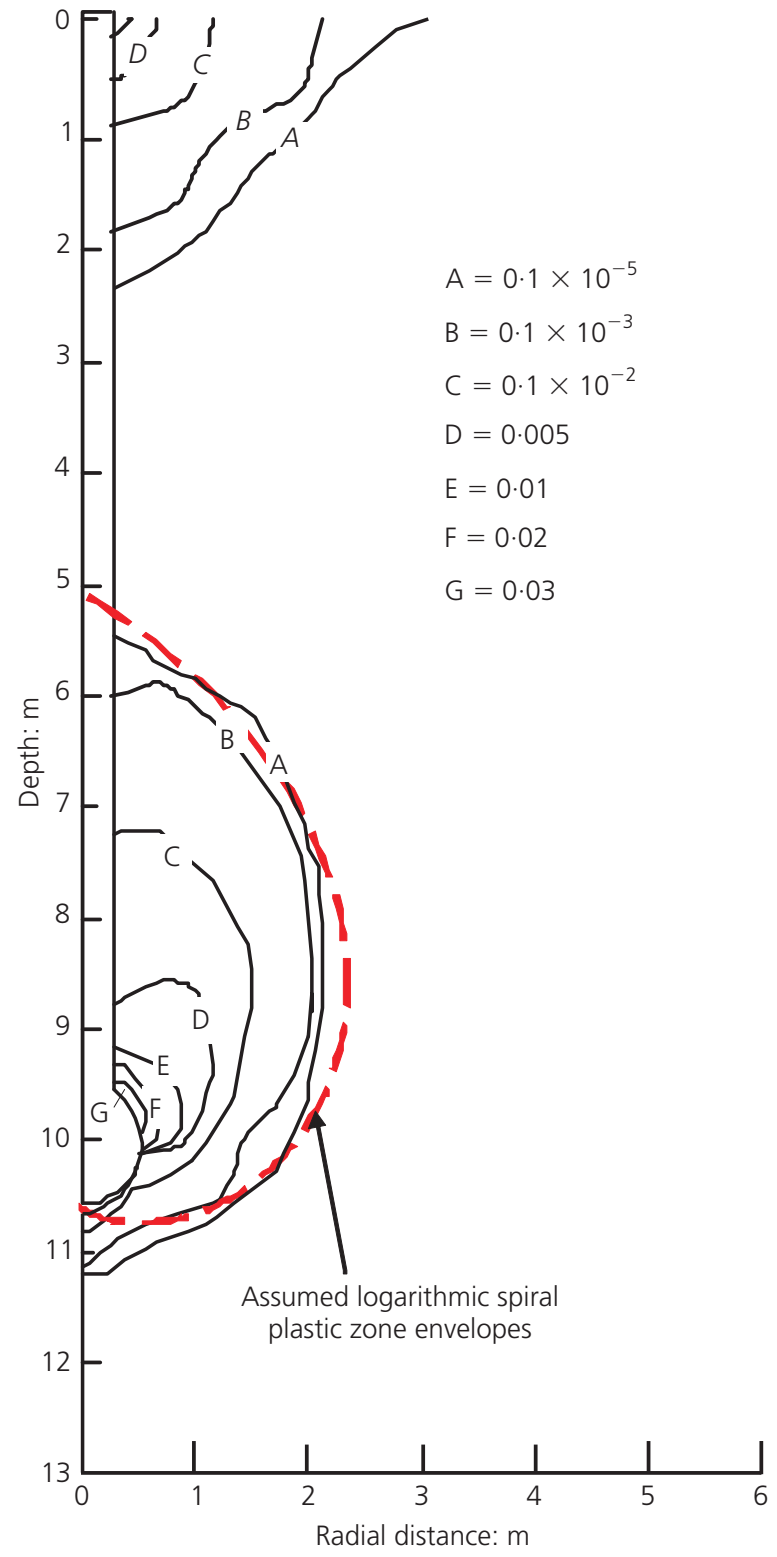

Figure 7. Contours of the accumulated equivalent plastic strains due to the pile uplifting for scheme No. 2 at the serviceability failure limit

the plastic zone would be slightly larger than that shown in Figure 7.

\subsection{Effect of enlarged base size}

It has been well recognised that there is a so-called size-effect on foundation bearing capacity. In this study, the effect of the enlarged base size has been examined on the uplift resistance and the plastic zones using the additional three schemes Nos 3, 4 and 5. In Figures 9, 10 and 11, the accumulated equivalent plastic strain contours in the soil are presented at the serviceability failure limit for the three schemes. 


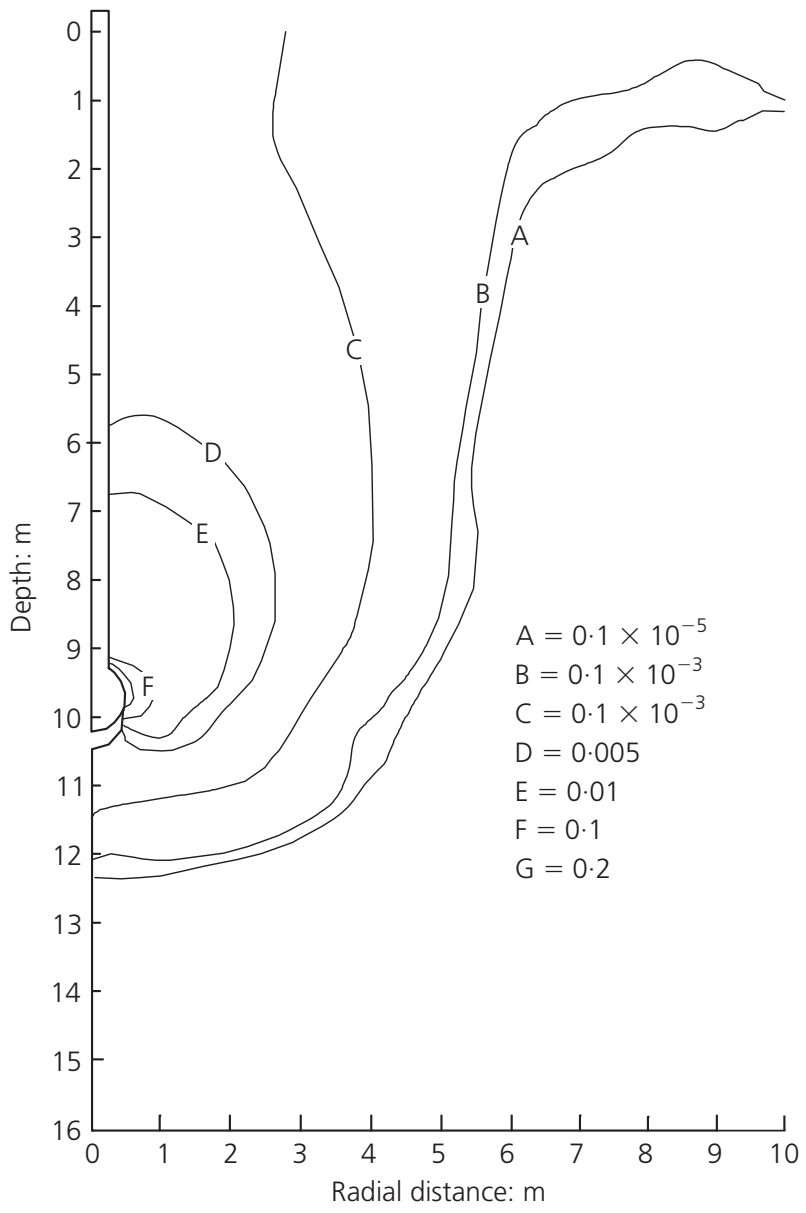

Figure 8. Contours of the accumulated equivalent plastic strains due to the pile uplifting for scheme No. 2 at the ultimate failure stage

From Figures 9, 10 and 11, it can be observed that the plastic strain contours have similar contour patterns to those in Figure 4, but the plastic zone increases as the base diameter $D$ enlarges. Using Equation 1, the logarithmic spiral function can be determined for each of the plastic strain contours A in Figures 9, 10 and 11. The functions are plotted as the dashed lines in the corresponding figures. The initial radii of the logarithmic spirals are estimated to be $0.84,1.22$ and $1.55 \mathrm{~m}$ for scheme Nos 3,4 and 5 with the base diameters $D=0.7,1.4$ and $1.8 \mathrm{~m}$, respectively.

Based on the above results, the following empirical equation is proposed for determining the initial radius of the logarithmic spiral function for the plastic zone at the serviceability failure limit of enlarged base pile uplifting.

$$
\begin{aligned}
r_{\mathrm{p} 0} & =\frac{1}{2} \beta_{1}(D-d) \exp \left[\beta_{2}(d / D)^{\beta_{3}}\right] \\
2 . \quad & =\frac{1}{2} \beta_{1}(n-1) d \exp \left(\beta_{2} n^{-\beta_{3}}\right)
\end{aligned}
$$

where $n=D / d$ and $\beta_{1}, \beta_{2}$ and $\beta_{3}$ are the unknown parameters.

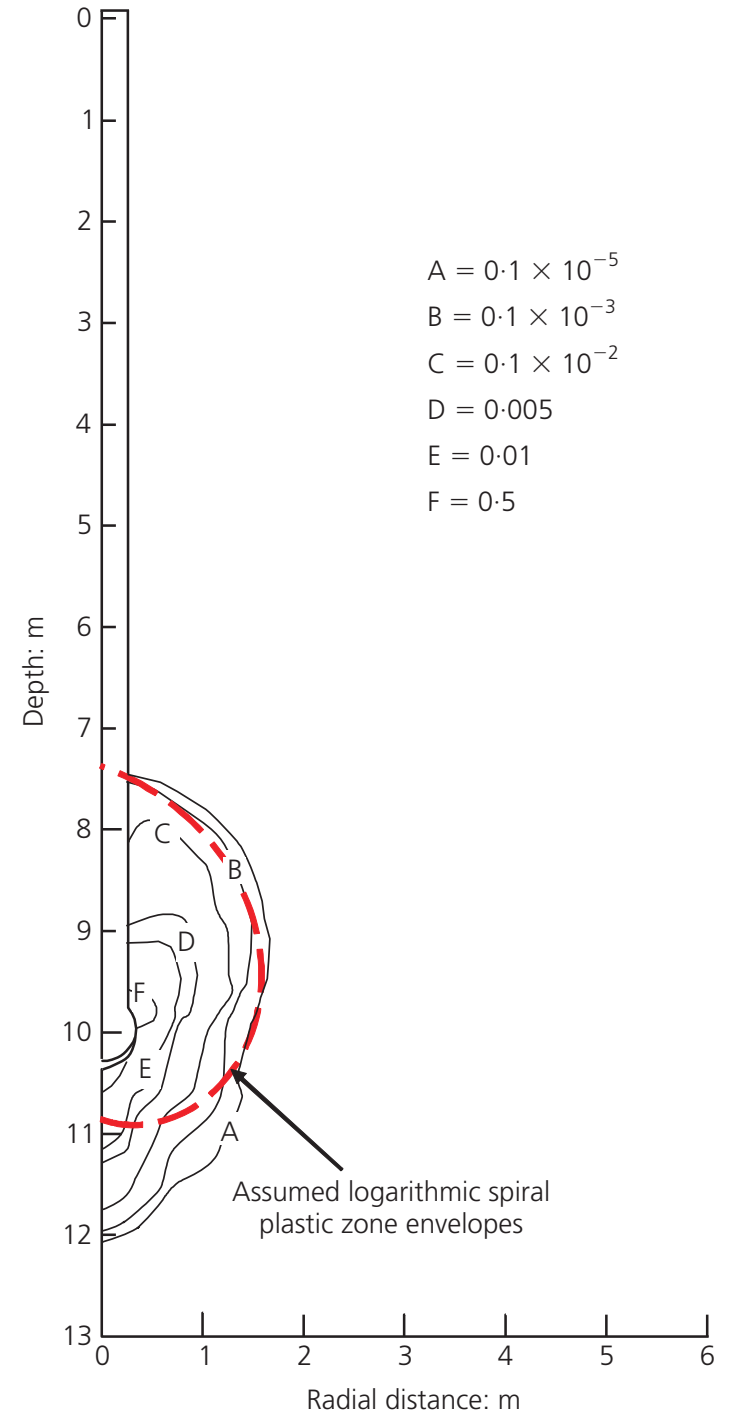

Figure 9. Contours of the accumulated equivalent plastic strains at the serviceability failure limit due to the pile uplifting for scheme No. 3

Using the above results from the four schemes Nos 1, 3, 4 and 5 in Table 2, the relations are plotted between $r_{\mathrm{p} 0} /[(D-d) / 2]$ and $D / d$ in Figure 12. Using a non-linear curve-fitting method, the best-fit three constant parameters can be determined as $\beta_{1}=1.50, \beta_{2}=2.786$ and $\beta_{3}=1.40$. Therefore, the initial radius can be specifically expressed as follows

$$
\begin{aligned}
r_{\mathrm{p} 0} & =\frac{3}{4}(D-d) \exp \left[2 \cdot 786(d / D)^{1 \cdot 4}\right] \\
& =\frac{3}{4}(n-1) d \exp \left(2 \cdot 786 / n^{1 \cdot 4}\right) k
\end{aligned}
$$

3. (for schemes Nos $1,3,4,5)$

that is, for schemes Nos $1,3,4,5\left(\phi=20^{\circ}\right), \beta_{1}=1 \cdot 50$, $\beta_{2}=2.786$ and $\beta_{3}=1.40$. 


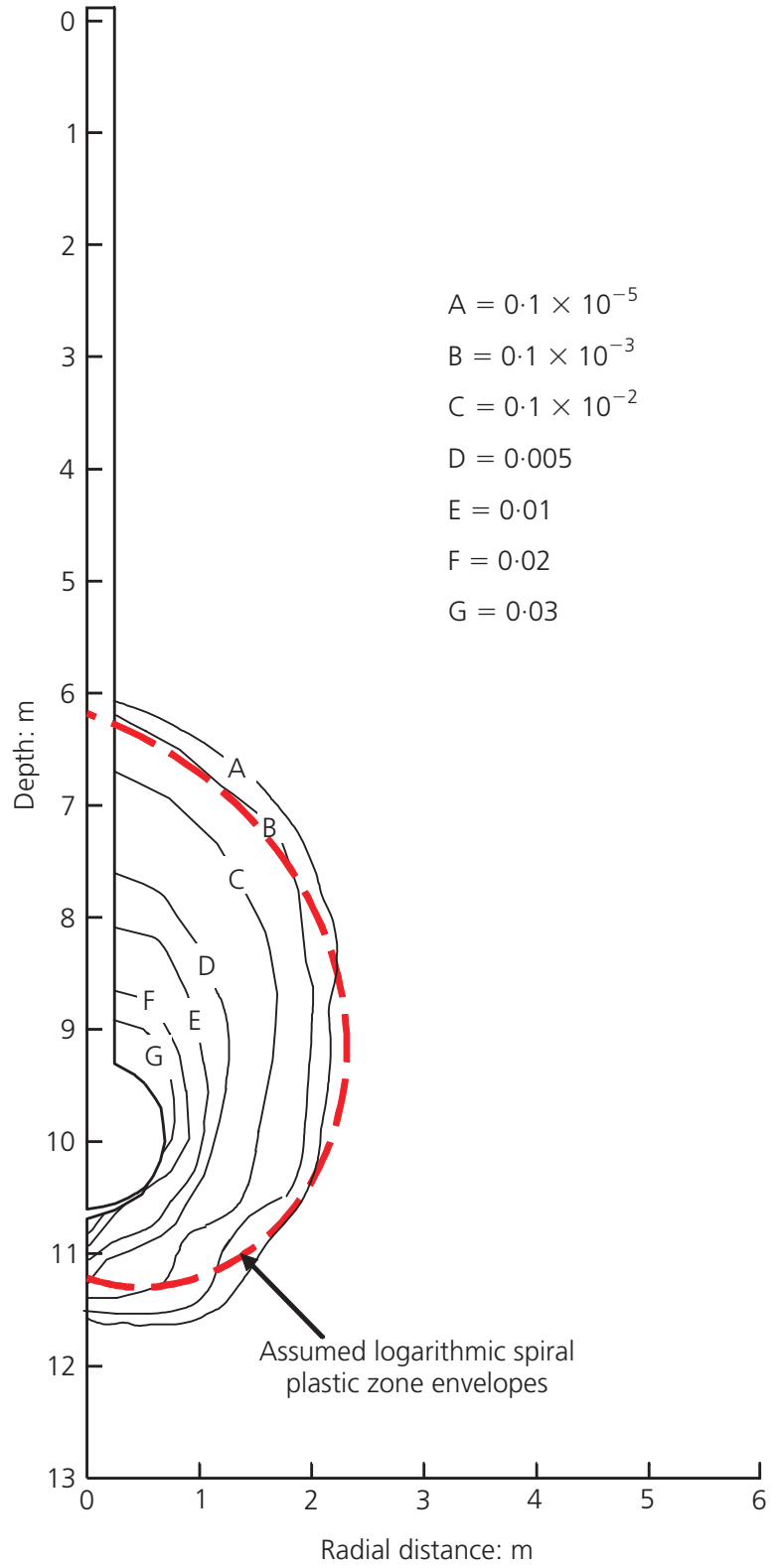

Figure 10. Contours of the accumulated equivalent plastic strains at the serviceability failure limit due to the pile uplifting for scheme No. 4

Similarly, using different base diameters for pile uplifting in the non-cohesive $(c=0)$ soil in scheme No. 2, the following equation is found to be adequate for the estimation of the initial radius.

$$
\begin{aligned}
r_{\mathrm{p} 0} & =\frac{3}{4}(D-d) \exp (d / D)^{1 \cdot 4} \\
& =\frac{3}{4}(n-1) d \exp \left(1 / n^{1 \cdot 4}\right)
\end{aligned}
$$

4. (for scheme No. 2)

that is, for scheme No. $2\left(\phi=35^{\circ}\right), \beta_{1}=1 \cdot 50, \beta_{2}=1 \cdot 0$ and $\beta_{3}=1 \cdot 40$

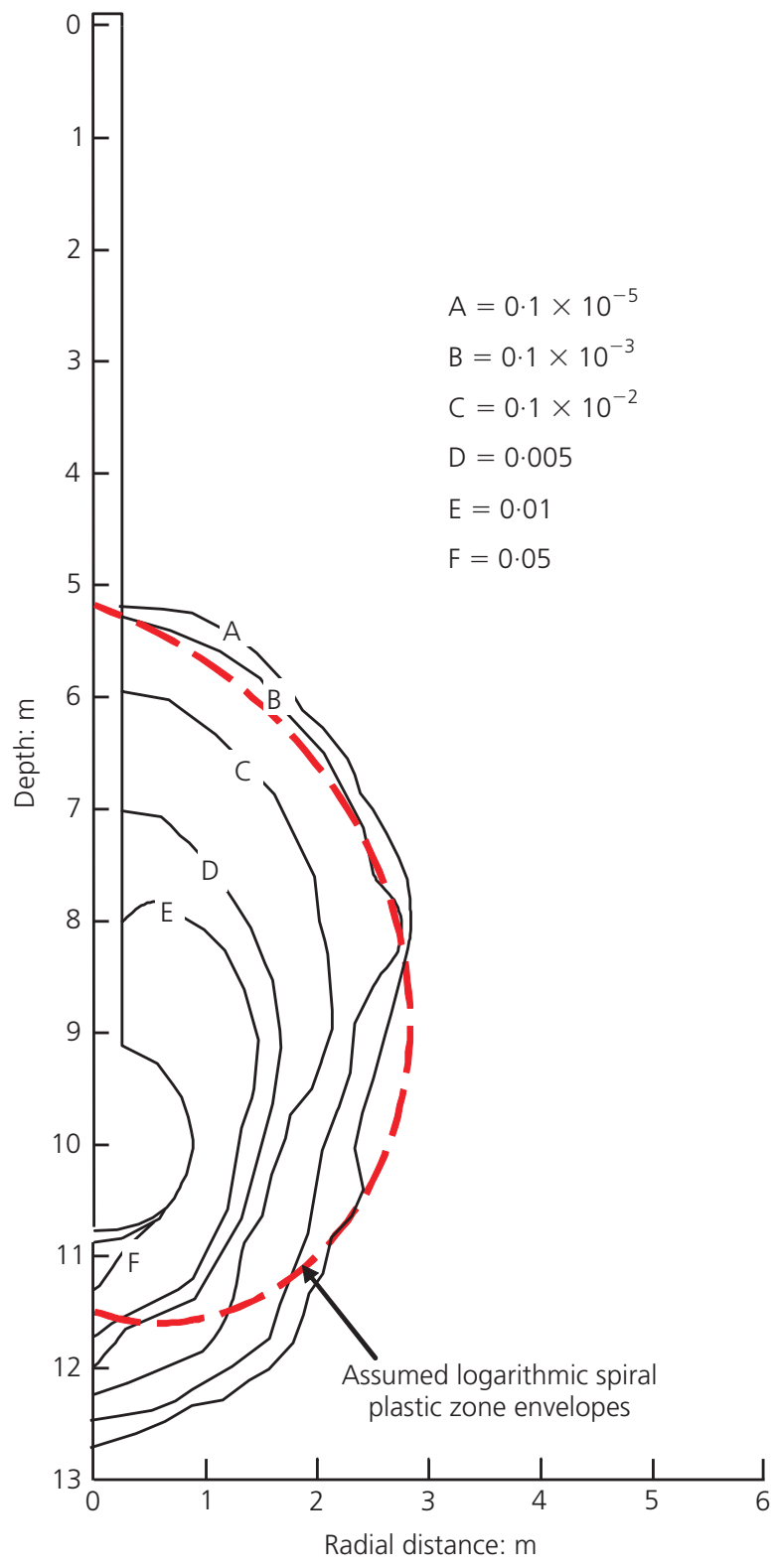

Figure 11. Contours of the accumulated equivalent plastic strains at the serviceability failure limit due to the pile uplifting for scheme No. 5

Taking into account the effect of the soil internal friction angle $\phi$ on the plastic failure zone, a unified equation can be established for estimating the initial radius from Equations 3 and 4. It is found that the following common unified Equation 5 can be used to accurately represent Equations 3 and 4.

$$
\begin{aligned}
r_{\mathrm{p} 0} & =\frac{3}{4}(D-d) \exp \left[6 \tan \left(\frac{\pi}{4}-\phi\right)(d / D)^{1 \cdot 4}\right] \\
& =\frac{3}{4}(n-1) d \exp \left[6 \tan \left(\frac{\pi}{4}-\phi\right) / n^{1 \cdot 4}\right]
\end{aligned}
$$

5. (common unified form) 


12

2

Cohesive
20
2.0
1.05

Cohesionless
35
2.0
0.54

$4 \cdot 20$

$2 \cdot 16$

$\beta_{1}=1.50$

1.08

and $\beta$

$-\phi)$

0.86

$+2 \cdot 86 \%$

0.56

$1 \cdot 31$

$1 \cdot 55$

$+0 \cdot 00 \%$

$+1 \cdot 85 \%$

$+6 \cdot 50 \%$

$+0 \cdot 00 \%$

$[=(B-A) / A]$

Table 2. Comparison of the initial radius values estimated from the FEM analysis and the logarithmic spiral function for the plastic strain zone envelopes in the soils induced by the pile uplifting at the serviceability failure limit

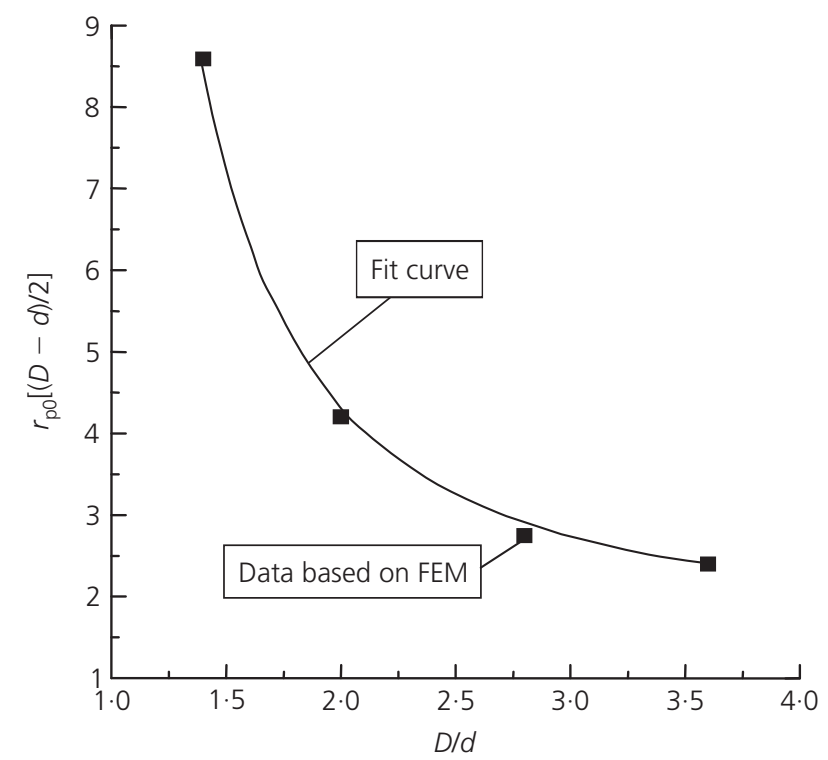

Figure 12. Estimating the relation between $r_{\mathrm{po}} /[(D-d) / 2]$ and $D / d$ in the cohesive soil for schemes Nos 1, 3, 4 and 5

that is, for common unified form, $\beta_{1}=1 \cdot 50, \beta_{2}=6 \tan (\pi / 4-\phi)$ and $\beta_{3}=1 \cdot 40$.

A numerical comparison of the above analysis and formulation is summarised in Table 2. The initial radii of the logarithmic spiral functions using Equation 5 are within $6.5 \%$ of those from the FEM analysis. Researching found that internal friction angle $\phi$ has larger effect, but the low-cohesive force $c$ (generally less than or equal to $10 \mathrm{kPa}$ ) has smaller effect on the plastic failure zone. Many literature studies (e.g. Prandtl, 1920; Meyerhof, 1951; Terzaghi, 1943) have shown that slip surface was taken as the logarithmic spiral surface (function about $\phi$ and not about $c$ ) to compute bearing capacity of shallow footings. Therefore, this paper takes into account only the effect of internal friction angle for equations with simplified mathematics.

\subsection{Soil slip surface for base resistance}

Using the above results on the plastic strain zones and the assumption that the boundary to this is a slip surface, the slip surface is often used to evaluate the enlarged base uplift resistance associated with a deep pile. In general, a plastic strain zone envelope is not exactly the same as that of a slip surface in the soil induced by a foundation. The plastic zone usually occupies a slightly larger soil region than the slip zone (Potts and Zdravkovic, 2001). Furthermore, the compressive deformation in soft soil (such as soil with small $\phi$, generally, $\phi<25^{\circ}$; or soil with small elastic modulus) is usually large, while it is small in hard soil (such as soil with large $\phi$, generally $\phi>30^{\circ}$; or soil with large elastic modulus). The slip surface should be much less than the plastic strain zone envelope in soft soil, but close to the plastic strain zone envelope in hard soil under uplift load.

Based on the above arguments, it can be concluded that the slip surfaces may lie between the contours $\mathrm{C}$ and $\mathrm{D}$ in Figures 4, 9, 10 and 11 for small $\phi$ soil and between the contours A and B in Figure 7 for large $\phi$ soil by means of a back-analysis comparing the base uplift resistances from the above FEM analysis with those estimated using the theoretical equation. Furthermore, it is assumed that the slip surface is similar to the plastic strain zone envelope and can be expressed as the following logarithmic spiral function in the polar coordinate system on any vertical plane

$$
\text { 6. } r=r_{0} \mathrm{e}^{\theta \tan \phi}
$$

where $r_{0}$ is the initial radius of logarithmic spiral slip surface. 
Using an analysis similar to the formulation of Equation 5, the following empirical equation is established for the estimation of the initial radius in Equation 6

$$
\begin{aligned}
r_{0} & =\frac{3}{4}(D-d) \exp \left[b \tan \left(\frac{\pi}{4}-\frac{\phi}{2}\right)(d / D)^{a}\right] \\
& =\frac{3}{4}(n-1) d \exp \left[b \tan \left(\frac{\pi}{4}-\frac{\phi}{2}\right) / n^{a}\right]
\end{aligned}
$$

7.

$$
=\bar{r}_{0} d
$$

where $\bar{r}_{0}$ is a dimensionless parameter and is defined as follows

$$
\text { 8. } \quad \bar{r}_{0}=\frac{3}{4}(n-1) \exp \left[b \tan \left(\frac{\pi}{4}-\frac{\phi}{2}\right) / n^{a}\right]
$$

where $a$ and $b$ are the constant parameters.

In Equations 7 and 8, the parameters $a$ and $b$ are two constants, which can be determined by comparing the base uplift resistances from the above FEM analysis with those estimated using the theoretical equation given after $\mathrm{Xu}$ et al. (2009) as follows

9.

$$
\begin{aligned}
Q_{\mathrm{bu}}= & \frac{1}{4} \pi\left(D^{2}-d^{2}\right) \\
& \times\left[c N_{c}+\xi_{\mathrm{D}} \gamma_{\mathrm{s}}^{\prime} z_{\mathrm{p}} N_{q}+\frac{1}{2}(D-d) \gamma_{\mathrm{s}}^{\prime \prime} N_{\gamma}\right]
\end{aligned}
$$

where $Q_{\mathrm{bu}}$ is the base uplift resistance capacity at the serviceability failure limit; $\xi_{\mathrm{D}}$ is the factor influencing the coefficient of lateral pressure acting on the pile shaft by the enlarged base at the serviceability failure limit, generally in the range $0 \cdot 8-1 \cdot 0 ; \gamma_{\mathrm{s}}^{\prime}$ is the soil effective unit weight above the plastic zone; $\gamma_{\mathrm{s}}^{\prime \prime}$ is the soil unit weight within the plastic zone; $\delta$ is the frictional angle between pile and soil; $z_{\mathrm{p}}$ is the depth to the vertex of the plastic zone envelope, $L-r_{\mathrm{p} 0} \mathrm{e}^{\pi \tan \phi} ; L$ is the buried pile length between the ground surface and the centre of the spherical base; $N_{c}, N_{q}$ and $N_{\gamma}$ are the base uplift resistance capacity factors that are defined as follows

$$
\text { 10. } N_{c}=\frac{24 \bar{r}_{0}^{3}\left(\mathrm{e}^{3 \pi \tan \phi}+1\right)}{\left[n^{3}-1+\tan \delta\left(n^{2}-1\right)^{1 \cdot 5}\right]\left(9 \tan ^{2} \phi+1\right)}
$$

$$
N_{q}=\frac{\begin{array}{c}
K_{0}\left\{12 \bar{r}_{0}^{2} \mathrm{e}^{2 \pi \tan \phi}+2 n^{3}-3 n^{2}+1\right. \\
\left.-\left[12 \bar{r}_{0} \mathrm{e}^{\pi \tan \phi}+4\left(n^{2}-1\right)^{1 \cdot 5}\right] \tan \delta\right\}
\end{array}}{2\left[n^{3}-1+\tan \delta\left(n^{2}-1\right)^{1 \cdot 5}\right]}
$$

$$
N_{\gamma}=\frac{\frac{3 \bar{r}_{0}^{4}\left(\mathrm{e}^{4 \pi \tan \phi}-1\right)}{2\left(4 \tan ^{2} \phi+1\right) \tan \phi}-2 \bar{r}_{0} \mathrm{e}^{\pi \tan \phi}+n-\frac{3}{8} \pi n^{4}}{(n-1)\left[n^{3}-1+\tan \delta\left(n^{2}-1\right)^{1 \cdot 5}\right]}
$$

where $K_{0}$ is the coefficient of earth pressure at rest.

At first, $\bar{r}_{0}$ is determined using the back-analysis method, see Table 3. Then the relations are plotted between $\bar{r}_{0} /(n-1)$ and $n$ on the low-cohesive soil in Figure 13. Using the non-linear curve-fitting method, the two constant parameters can be determined as $a=2.5$ and $b=3.75$. Therefore, the dimensionless initial radius for low-cohesive soil can be specifically expressed as follows

13. $\bar{r}_{0}=\frac{3}{4}(n-1) \exp \left[3.75 \tan \left(\frac{\pi}{4}-\frac{\phi}{2}\right) / n^{2.5}\right]$

Using Equation 13 to compute the dimensionless initial radius of scheme No. 2 in non-cohesive soil (see Table 3 ), $\bar{r}_{0}$ is equal to 1.0257 , close to 1.0591 obtained by back-analysis. Therefore, Equation 13 is also suitable for $c=0$ soil.

Table 3 gives also a comparison between the results estimated using the FEM analysis and Equations 7, 8 and 13 for the initial radius of the slip surface at the serviceability failure limit. The two results are in close agreement.

Using Equations 6, 7, 8 and 13, a parametric study is carried out on the effect of the two parameters $n$ and on the slip surface associated with the pile uplifting at the serviceability failure limit. The results are presented in Figure 14. The solid curves in the right-hand part of Figure 14 show the effect of the $n$ value on the slip surface, where $b=3 \cdot 75, \phi=20^{\circ}, d=0.5 \mathrm{~m}$ and $a=2.5$. It is evident that the larger the $n$ value is, the larger the slip surface will be. The dashed curves on the right of Figure 14 show the effect of the $\phi$ value on the slip surface, where $b=3.75$, $n=2, \quad d=0.5 \mathrm{~m}, a=2.5$. The slip surface enlarges as $\phi$ increases. Furthermore, the parameter $b$ can be used to indicate the effect of the pile head uplift displacement on the slip surface. The slip surface curves are plotted for a wide range of $b$ values as shown in Figure 14, where $\phi=20^{\circ}, n=2, d=0.5 \mathrm{~m}, a=2.5$. It is shown that the slip surface enlarges as $b$ increases, which is consistent with the continuous increase in the base resistance as the pile head upward displacement increases. It is evident that axisymmetrical rotation of the two-dimensional slip surfaces in 


\begin{tabular}{|c|c|c|c|c|c|c|}
\hline \multicolumn{2}{|c|}{ Scheme No. } & 3 & 1 & 2 & 4 & 5 \\
\hline \multicolumn{2}{|c|}{ Soil type } & Low-cohesive & Low-cohesive & Non-cohesive & Low-cohesive & Low-cohesive \\
\hline \multicolumn{2}{|c|}{$n(=D / d)$} & 1.4 & $2 \cdot 0$ & $2 \cdot 0$ & $2 \cdot 8$ & 3.6 \\
\hline \multicolumn{2}{|c|}{$\phi:$ deg } & 20 & 20 & 35 & 20 & 20 \\
\hline \multirow{2}{*}{\multicolumn{2}{|c|}{$\mathrm{c}: \mathrm{kPa}$}} & 10 & 10 & 0 & 10 & 10 \\
\hline & & 0.81 & 0.81 & 0.67 & 0.81 & 0.81 \\
\hline \multicolumn{2}{|c|}{ Pile diameter, $d: m$} & 0.5 & 0.5 & 0.5 & 0.5 & 0.5 \\
\hline \multicolumn{2}{|c|}{ Pile length, $L: m$} & 10 & 10 & 10 & 10 & 10 \\
\hline \multirow{2}{*}{\multicolumn{2}{|c|}{$\begin{array}{l}\text { Enlarged base ball diameter, } D: m \\
n(=D / d)\end{array}$}} & $0 \cdot 7$ & $1 \cdot 0$ & $1 \cdot 0$ & $1 \cdot 4$ & $1 \cdot 8$ \\
\hline & & 1.4 & $2 \cdot 0$ & $2 \cdot 0$ & $2 \cdot 8$ & $3 \cdot 6$ \\
\hline \multicolumn{2}{|c|}{ Soil unit weight, $\gamma_{s}: k N / m^{3}$} & 18 & 18 & 18 & 18 & 18 \\
\hline \multicolumn{2}{|c|}{ Pile unit weight, $\gamma_{p}: k N / m^{3}$} & 25 & 25 & 25 & 25 & 25 \\
\hline \multicolumn{2}{|c|}{$\begin{array}{l}\text { Base uplift resistance capacity of finite- } \\
\text { element result (Xu et al., 2009): kN }\end{array}$} & $612 \cdot 30$ & $857 \cdot 60$ & $1975 \cdot 50$ & $1647 \cdot 20$ & $2604 \cdot 80$ \\
\hline \multirow[t]{3}{*}{$\bar{r}_{0}$} & $\begin{array}{l}\text { Back-analysis result using } \\
\text { Equation } 12(A)\end{array}$ & 0.9317 & $1 \cdot 1945$ & 1.0257 & 1.6733 & $2 \cdot 1133$ \\
\hline & $\begin{array}{l}\text { Equation } 16 \text { result } \\
(a=2 \cdot 5, b=3 \cdot 75, \text { using non- } \\
\text { linear fit with Equation } 11 \text { in } \\
\text { Figure } 12)(B)\end{array}$ & 0.9308 & $1 \cdot 1930$ & 1.0591 & $1 \cdot 6491$ & $2 \cdot 1698$ \\
\hline & $(B-A) / A \times 100 \%$ & $-0 \cdot 10 \%$ & $-0 \cdot 13 \%$ & $3 \cdot 26 \%$ & $-1 \cdot 45 \%$ & $2 \cdot 67 \%$ \\
\hline \multirow[t]{2}{*}{$r_{0}: m$} & $\begin{array}{l}\text { Estimation range from FEM } \\
\text { results }\end{array}$ & $0.32-0.66$ & $0.61-0.82$ & $0.52-0.56$ & $0.76-1.02$ & $0.96-1.27$ \\
\hline & Equation 10 result & 0.4654 & 0.5965 & 0.5296 & 0.8246 & 1.0849 \\
\hline
\end{tabular}

Table 3. Comparison of the initial radius values of back-analysis, estimated from the FEM analysis and the logarithmic spiral function for the slip surfaces in the soils induced by the pile uplifting at the serviceability failure limit

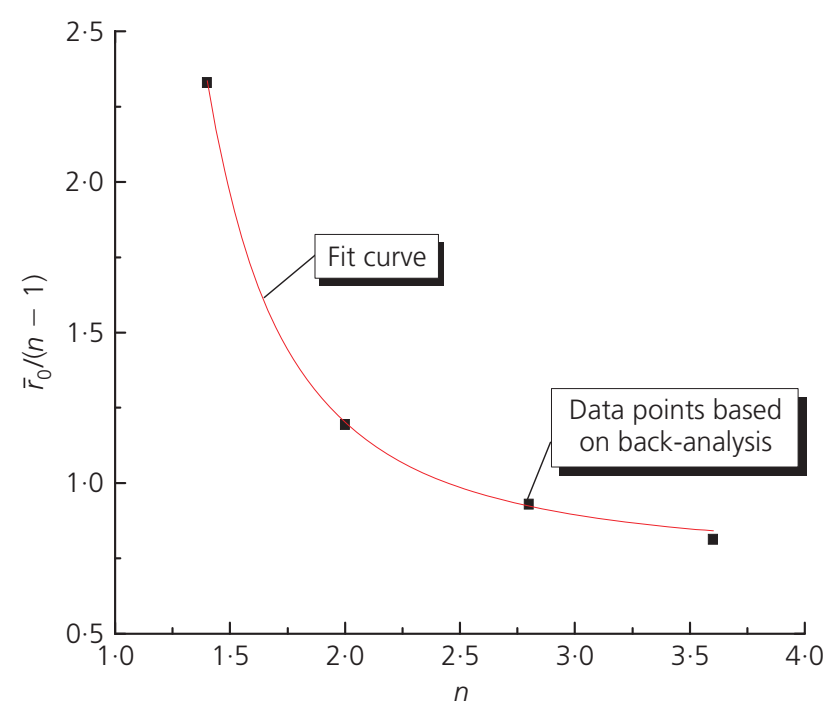

Figure 13. Estimating the relation between $\bar{r}_{0} /(n-1)$ and $n$ in the cohesive soil for schemes Nos 1, 3, 4 and 5
Figure 14 forms a series of axisymmetrical peach-shaped, closed and curved surfaces within the ground soils.

\section{Summary and conclusion}

In this paper a FEM analysis has been presented of deep piles with enlarged spherical base subject to uplift load. The piles are embedded in $\phi, c$ or $\phi, c=0$ soils. Based on the findings of the FEM analysis, a plastic zone envelope model and a slip surface model for the pile uplifting have been established. The soil plastic yielding starts at the region near the enlarged base and propagates gradually upwards with the increase in the pile upward displacement until the ultimate failure stage. At the ultimate failure stage, the uplift displacement is very large; for example, ultimate failure displacement is $396.4 \mathrm{~mm}$ for scheme No. 1 and $301.8 \mathrm{~mm}$ for scheme No. 2. Therefore it is suggested that the serviceability failure limit stage be reached as the limit upward displacement equals $10 \%$ of the least pile diameter.

Using the plastic strain contours in the soil adjacent to the enlarged spherical base at the serviceability failure limit, the logarithmic spiral functions are established governing the plastic 


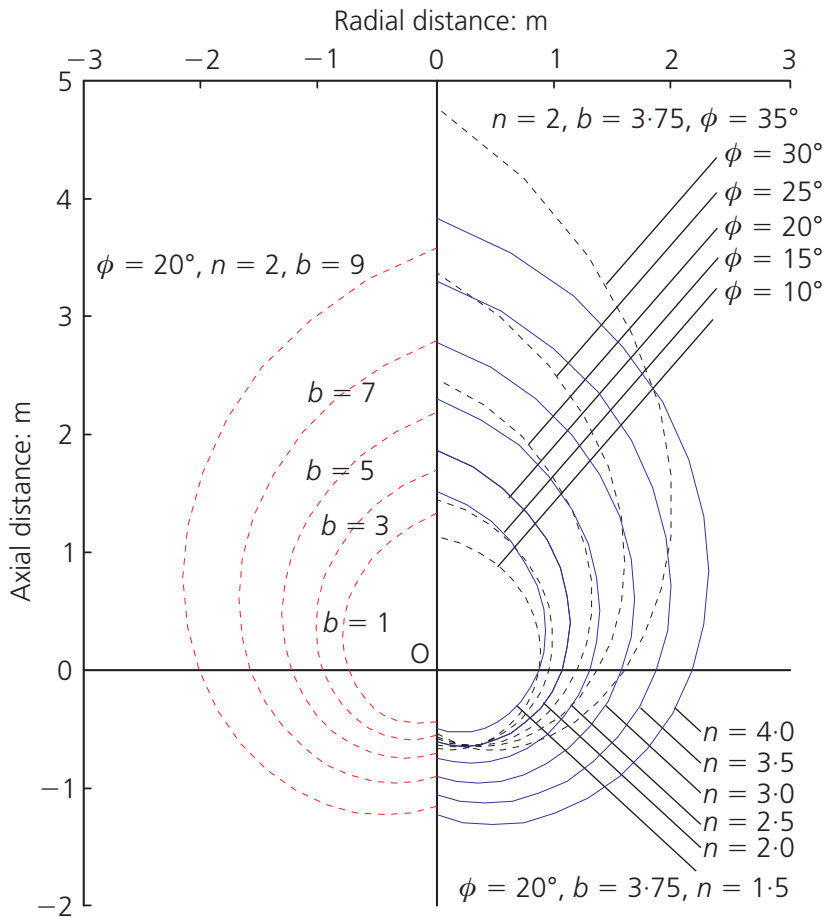

Figure 14. Variations of the estimated logarithmic spiral slip surfaces with different soil and pile parameters, where the pile shaft diameter $d=0.5 \mathrm{~m}$

zone envelopes and the slip surfaces. Using the equations, the plastic zone envelopes and slip surfaces can be accurately and efficiently estimated using the ratio of the enlarged spherical base diameter over the pile shaft diameter, the soil internal friction angle and the pile shaft diameter. The plastic zone corresponds to the lower constant portion of the unit skin frictional resistance model. The plastic zone envelopes and slip surfaces are axisymmetrical, peach-shaped, closed and curved surfaces, completely beneath the ground surface.

\section{Acknowledgements}

The authors would like to thank the Research Grants Council of Hong Kong SAR Government, the Hong Kong Jockey Club Charities Trust and the National Basic Research Program of China (973 Program No. 2008CB724608) for their financial support.

\section{REFERENCES}

Alawneh AS, Malkawi AIH and Al-Deeky H (1999) Tension tests on smooth and rough model piles in dry sand. Canadian Geotechnical Journal 36(4): 746-753.

Al-Mhaidib Al and Edil TB (1998) Model tests for uplift resistance of piles in sand. Geotechnical Testing Journal 21(3): 213-221.

Balaam NP, Poulos HG and Booker JR (1975) Finite element analysis of the effects of installation on pile load-settlement behavior. Geotechnical Engineering 6(1): 33-48.

Chattopadhyay BC and Pise PJ (1986) Uplift capacity of piles in sand. Journal of the Geotechnical Engineering Division, ASCE 112(9): 888-904.

Dickin EA and Leung CF (1990) Performance of piles with enlarged base subject to uplift forces. Canadian Geotechnical Journal 27(5): 546-556.

Dickin EA and Leung CF (1992) The influence of foundation geometry on the uplift behaviour of piles with enlarged base in sand. Canadian Geotechnical Journal 29(3): 498-505.

Ellison RD, D'Appolnia E and Thiers GR (1971) Load deformation mechanism for bored piles. Journal of Soil Mechanics and Foundation Division, ASCE 97(4): 661-678.

GEO (Geotechnical Engineering Office) (1996) Pile Design and Construction. Geotechnical Engineering Office, Hong Kong Government, Hong Kong, p. 160.

Ghaly AM (1999) Discussion: Uplift behaviour of cylindrical anchors in sand. Canadian Geotechnical Journal 36(3): 573 574.

Guruno SB, Nakazima Y, Sakajo S and Kusakabe O (1998) Centrifugal modeling of enlarged base foundation subjected to pull-out force. Japanese Geotechnical Society, Journal of Soils and Foundations 38(4): 105-113.

Hsu ST and Liao HJ (1998) Uplift behaviour of cylindrical anchors in sand. Canadian Geotechnical Journal 35(1): 70-80.

Ilamparuthi K and Dickin EA (2000) Numerical modelling of the uplift behaviour of circular plate anchors in sand. In Computational Civil and Structure Engineering (Roeck G De and Topping BHV (eds)). Civi-Comp Press, Edinburgh, UK, pp. 249-256.

Ilamparuthi K and Dickin EA (2001a) The influence of soil reinforcement on the uplift behaviour of belled piles embedded in sand. Geotextiles and Geomembranes 19(1): $1-22$.

Ilamparuthi K and Dickin EA (2001b) Predictions of the uplift response of model belled piles in geogrid-cell-reinforced sand. Geotextiles and Geomembranes 19(2): 89-109.

Ireland HO (1957) Pulling tests on piles in sand. Proceedings of the 4th International Conference on Soil Mechanics and Foundation Engineering, London. Butterworths Scientific Publications, London, UK, vol. 2, pp. 43-45.

Ismael NF and Al-Sanad HA (1986) Uplift capacity of bored piles in calcareous soils. Journal of Geotechnical Engineering, ASCE 112(10): 928-939.

Kohnke P (1997) ANSYS Theory Reference (Release 5.4). ANSYS, Inc, Canonsburg, PA, USA.

Kulhawy FH (1985) Uplift behavior of shallow soil anchors - an overview. In Uplift Behavior of Anchor Foundations in Soil (Clemence SP (ed.)). ASCE, New York, NY, USA, pp. 1-25.

Lee CJ, Bolton MD and Al-Tabbaa A (2002) Numerical modelling of group effects on the distribution of drag loads in pile foundations. Géotechnique 52(5): 325-335.

Levacher DR and Sieffert JG (1984) Tests on model tension piles. Journal of Geotechnical Engineering, ASCE 110(12): $1735-1748$.

Liyanapathiranal DS, Deeks AJ and Randolph MF (2000) Numerical modelling of large deformations associated with 
driving of open-ended piles. International Journal for Numerical and Analytical Methods in Geomechanics 24(14): 1079-1101.

Lutenegger AJ and Adams MT (1999) Tension tests on bored piles in residual soil. In Behavioral Characteristics of Residual Soils (Edelen W (ed.)). ASCE, Charlotte, NC, USA, Geotechnical Special Publication No. 92, pp. 43-53.

Lutenegger AJ and Miller GA (1994) Uplift capacity of small diameter drilled shafts in stiff clay. Journal of Geotechnical Engineering, ASCE 120(8): 1362-1380.

Mathews MC, Clayton CRI and Bica AVD (2000) Tension pile tests in chalk. Quarterly Journal of Engineering Geology and Hydrogeology 33(3): 201-212.

Meyerhof GG (1951) The ultimate bearing capacity of foundations. Géotechnique 2(4): 301-331.

Meyerhof GG and Adams JI (1968) The ultimate uplift capacity of foundations. Canadian Geotechnical Journal 5(4): $225-244$.

Mohamedzein YEA, Mohamed MG and Sharief AME (1999) Finite element analysis of short piles in expansive soils. Computers and Geotechnics 24(3): 231-243.

Peric D and Owen DRJ (1992) Computational model for 3-D contact problems with friction based on the penalty method. International Journal for Numerical Method in Engineering 35(6): 1289-1309.
Potts DM and Zdravkovic L (2001) Finite Element Analysis in Geotechnical Engineering: Application. Thomas Telford, London, UK, pp. 220-229.

Prandtl L (1920) Über die Härte plastischer Körper. In Nachrichten, von der Koniglichen Gesellschaft der Wissenschaften zu Göttingon, Mathematisch-physikelische Klasse aus dem Jahre 1920. Weidmannsche Buchhandlung, Berlin, Germany, pp. 74-85 (in German).

Ronold KO (1990) Reliability analysis of tension pile. Journal of Geotechnical Engineering, ASCE 116(5): 760-773.

Ronold KO (1998) Reliability-based optimization of design code for tension piles. Journal of Geotechnical and Geoenvironmental Engineering, ASCE 125(8): 690-695.

Terzaghi K (1943) Theoretical Soil Mechanics. Wiley, New York, NY, USA.

Tomlinson MJ (1981) Pile Design and Construction Practice. Viewpoint Publications, London, UK, pp. 214 and 387.

Xu H-F, Wu HJ and Guo SP (2002) Study on the parameters of pile soil contact surface element. Exploration Engineering 29(5): 10-12 (in Chinese).

Xu H-F, Yue ZQ and Qian QH (2009) Predicting uplit resistance of deep piles with enlarged bases. Proceedings of the Institution of Civil Engineers - Geotechnical Engineering 162(4): 225238.

\section{WHAT DO YOU THINK?}

To discuss this paper, please email up to 500 words to the editor at journals@ice.org.uk. Your contribution will be forwarded to the author(s) for a reply and, if considered appropriate by the editorial panel, will be published as a discussion in a future issue of the journal.

Proceedings journals rely entirely on contributions sent in by civil engineering professionals, academics and students. Papers should be 2000-5000 words long (briefing papers should be 1000-2000 words long), with adequate illustrations and references. You can submit your paper online via www.icevirtuallibrary.com/content/journals, where you will also find detailed author guidelines. 